\title{
Baicalein, unlike 4-hydroxytamoxifen but similar to G15, suppresses 17ß-estradiol-induced cell invasion, and matrix metalloproteinase-9 expression and activation in MCF-7 human breast cancer cells
}

\author{
YAN CHEN $^{1,2^{*}}$, DUAN-YANG HONG ${ }^{1}{ }^{*}$, JING WANG $^{1}$, JUN LING-HU $^{2}$, YAN-YAN ZHANG ${ }^{1}$, \\ DI PAN ${ }^{1,2}$, YI-NI XU ${ }^{1}$, LING TAO $^{1}$, HONG LUO $^{1}$ and XIANG-CHUN SHEN ${ }^{1,2}$ \\ ${ }^{1}$ Key Laboratory of Optimal Utilization of Natural Medicine Resources and ${ }^{2}$ Department of Pharmacology \\ of Chinese Materia Medica, Guizhou Medical University, Guiyang, Guizhou 550004, P.R. China
}

Received October 3, 2015; Accepted March 17, 2017

DOI: $10.3892 / 01.2017 .6298$

\begin{abstract}
Estrogen performs an important role in the growth and development of breast cancer. There are at least three major receptors, including estrogen receptor (ER) $\alpha$ and $\beta$, and $\mathrm{G}$ protein-coupled receptor 30 (GPR30), which mediate the actions of estrogen through using transcriptional and rapid non-genomic signaling pathways. Flavonoids have been considered candidates for chemopreventive agents in breast cancer. Baicalein, the primary flavonoid derived from the root of Scutellaria baicalensis Georgi, has been reported to exert an anti-estrogenic effect. In the present study, the effects of baicalein on $17 \beta$-estradiol (E2)-induced cell invasion, and matrix metalloproteinase-9 (MMP-9) expression and activation were investigated. Furthermore, its effects were compared with that of the active form of the ER modulator tamoxifen 4-hydroxytamoxifen (OHT) and the GPR30 antagonist G15 in ER $\alpha$ - and GPR30-positive MCF-7 breast cancer cells. The results demonstrated that OHT failed to prevent E2-induced cell invasion, upregulation and proteolytic activity of MMP-9. However, baicalein was able to significantly suppress these E2-induced effects. Furthermore, E2-stimulated invasion, and MMP-9 expression and activation were significantly attenuated following G15 treatment. In addition, baicalein significantly inhibited G-1, a specific GPR30 agonist, induced invasion, and reduced G-1 promoted expression and activity of MMP-9, consistent with effects of G15. The results of the
\end{abstract}

Correspondence to: Professor Xiang-Chun Shen, Department of Pharmacology of Chinese Materia Medica, Guizhou Medical University, 9 Beijing Road, Guiyang, Guizhou 550004, P.R. China E-mail: shenxiangchun@126.com

*Contributed equally

Key words: baicalein, estrogen, $\mathrm{G}$ protein-coupled receptor 30, breast cancer, matrix metalloproteinase 9, tamoxifen present study suggest that baicalein is a therapeutic candidate for GPR30-positive breast cancer treatment, and besides ER $\alpha$ targeting the GPR30 receptor it may achieve additional therapeutic benefits in breast cancer.

\section{Introduction}

It is well known that the steroid hormone estrogen performs a role in the pathogenesis of breast cancer, and the majority of breast cancer types involve estrogen signaling pathways in cancer initiation, progression and metastasis (1). The majority of estrogen-associated biological actions are traditionally attributed to activate classic estrogen receptors (ERs), ER $\alpha$ and $\operatorname{ER} \beta$ (2). Thus, endocrine therapies that interfere with ER functions are currently applied in patients with ER-positive breast cancer. Although targeted inhibition of ER $\alpha$ is a successful approach, numerous patients fail to respond (de novo resistance) or relapse despite an initial response (acquired resistance) to anti-estrogen therapy (3). The selective ER modulator tamoxifen, which antagonizes estrogen-induced genomic-nuclear ER $\alpha$ activity, is widely used in the treatment of ER $\alpha$-positive breast cancer. It has significantly reduced the mortality risk among patients, however, not all patients achieve beneficial effects as disease recurrence occurs in $25-30 \%$ of patients (4).

The identification and characterization of the $G$ protein-coupled receptor 30 (GPR30) represents an additional mechanism of estrogen effects, which mediate a wide range of estrogenic responses, leading to changes in gene expression and relevant biological responses (5). It has been revealed that GPR30 expression is associated with clinical and pathological biomarkers of poor outcome in breast cancer (6). In addition, GPR30 is overexpressed in invasive breast cancer and positively correlated with the development of distant metastases, furthermore, mouse mammary tumor virus-polyoma middle $\mathrm{T}$ (MMTV-PyMT) mice deficient in GPR30 expression exhibit a substantially decreased incidence of metastasis compared with GPR30 wild-type (6-8). These observations suggest that GPR30 is implicated in breast cancer metastasis and 
may provide a novel potential target for treatment. Although tamoxifen exhibits antagonistic properties with respect to $\mathrm{ER} \alpha$, it performs as a GPR30 agonist (9), which demonstrates the complex physiological and therapeutic actions it possesses.

Tumor metastasis consists of a series of relevant biological processes including cell adhesion, migration, and invasion. Degradation extracellular matrix (ECM) of tumor cells is a hallmark of tumor metastasis and an essential step for invading distant organs (10). The expression and activation of matrix metalloproteinases (MMPs) facilitate tumor cells to invade the ECM underlying their basement membrane and stroma (11). Among the MMPs, MMP-2 and MMP-9, two zinc-dependent endopeptidases, perform essential roles in ECM degradation. Overexpression of MMP-2 and MMP-9 were associated with high potential of metastasis and they are poor prognostic factors in patients with breast cancer (12). A positive association between GPR30 and MMP-9 expression was identified in malignant ovarian endometriotic cysts and epithelial ovarian cancer $(13,14)$. Furthermore, E2 and selective GPR30 agonist G-1 increased the expression and proteolytic activity of MMP-9 in ovarian cancer cells, which could be inhibited by small interfering RNA targeting GPR30 or G protein inhibitor pertussin toxin (15), indicating a possible linkage between GPR30 and MMP-9. Nevertheless, the contribution of GPR30 in the regulation of MMP-9 in breast cancer cells remains unclear.

The incidence of breast cancer is much higher in Western countries compared with in Asian countries. Certain epidemiological studies contribute one factor of these differences to dietary flavonoids (16-18). Furthermore, as their polyphenolic ring is similar to the steroid nucleus of $17 \beta$-estradiol (E2), certain flavonoids have been considered to exert an anti-estrogenic effect and are candidates for chemopreventive agents to reduce the risk of breast cancer (19). Baicalein (5,6,7-trihydroxyflavone) is the primary flavonoid derived from Scutellaria baicalensis Georgi, whose structure is composed of a three-ring flavone backbone with phenolic hydroxyl at the 5', 6', and 7' position. Several studies have revealed that baicalein possesses antitumor activity in breast cancer and exhibits anti-estrogenic activity (20-22). In our previous study, it was demonstrated that baicalein is able to suppress E2 enhanced migration, adhesion and invasion of breast cancer cells and interferes with E2 or G-1 induced GPR30 signaling activation (23). However, whether this compound could inhibit E2 promoted MMP-9 upregulation and activation, as well as take effects via GPR30 remains unclear.

In the present study, the role of GPR30 in the regulation of the invasion process was evaluated, and the effects of baicalein on E2-induced cell invasion, MMP-9 activity and expression were investigated in ER $\alpha /$ GPR30-positive MCF-7 human breast cancer cells. In addition, the effects of baicalein with the active form of the selective ER modulator tamoxifen 4-hydroxytamoxifen (OHT) and the GPR30 antagonist G15.

\section{Materials and methods}

Reagents and antibodies. Baicalein (purity >98\%) was provided by Professor Qinglong Guo and Zhiyu Li (China Pharmaceutical University, Nanjing, China). It was dissolved in dimethyl sulfoxide (DMSO) as a stock solution at $0.1 \mathrm{M}$ and stored at $-20^{\circ} \mathrm{C}$. E2 (cat. no. E2758) and OHT (cat. no. H7904) were dissolved in DMSO as a stock solution at $10^{-1} \mathrm{M}$ and stored at $4^{\circ} \mathrm{C}$ (both from Sigma-Aldrich; Merck KGaA, Darmstadt, Germany). G-1 (cat. no. 10008933) and G15 (cat. no. 14,673) were purchased from Cayman Chemical Company (both from Ann Arbor, MI, USA) and dissolved in DMSO as a stock solution at $10^{-1} \mathrm{M}$ and stored at $-20^{\circ} \mathrm{C}$. Matrigel (cat. no. 356237) was obtained from BD Biosciences (Franklin Lakes, NJ, USA). Primary antibodies directed against MMP-9 (W680) (cat. no. BS1241; polyclonal rabbit anti-human; dilution 1:1,000), and GAPDH (1A6) (cat. no. MB001; monoclonal mouse anti-human; dilution, 1:4,000) were purchased from Bioworld Technology, Inc. (St. Louis Park, MN, USA). The anti-mouse (cat. no. sc-2005) or anti-rabbit (cat. no. sc-2030) ImmunoglobulinG horseradish peroxidase-conjugated secondary antibodies (dilution, 1:3,000) were purchased from Santa Cruz Biotechnology, Inc. (Dallas, TX, USA).

Cell culture and treatment. The human breast cancer MCF-7 cell line from the Kunming Cell Bank of the Chinese Academy of Sciences (Kunming, China) was maintained in DMEM (Hyclone; GE Healthcare Life Sciences, Logan, UT, USA) with $10 \%$ fetal bovine serum (FBS; Gibco, Thermo Fisher Scientific, Inc., Waltham, MA, USA), $100 \mathrm{U} / \mathrm{ml}$ penicillin and $100 \mu \mathrm{g} / \mathrm{ml}$ streptomycin (both from Sigma-Aldrich; Merck $\mathrm{KGaA}$ ). The cells were incubated at $37^{\circ} \mathrm{C}$ in a humidified atmosphere with $5 \% \mathrm{CO}_{2}$. Prior to the indicated treatments, cells were pre-cultured for $24 \mathrm{~h}$ at $37^{\circ} \mathrm{C}$ in phenol red (PR)-free DMEM (Hyclone; GE Healthcare Life Sciences, Logan, UT, USA) without serum to remove endogenous estrogen. Subsequently, cells were treated accordingly in PR-free DMEM (Hyclone; GE Healthcare Life Sciences). Control cells were incubated in DMSO $(0.01 \% \mathrm{v} / \mathrm{v})$. The concentrations of each drug were used as follows: E2 (1 nM), OHT (1 $\mu \mathrm{M}), \mathrm{G} 1(1 \mu \mathrm{M})$, $\mathrm{G} 15(1 \mu \mathrm{M})$ and baicalein $(10 \mu \mathrm{M})$.

Invasion assay. Invasive ability of cells was measured using an assay in a Transwell chamber (EMD Millipore, Billerica, MA, USA) containing membranes with an $8-\mu \mathrm{m}$ pore size, coated with Matrigel as previously described (24). Following treatment, cells were trypsinized and suspended at a final concentration of $5 \times 10^{5}$ cells $/ \mathrm{ml}$ in serum-free PR-free DMEM. The cell suspension was then added into each 10-mm upper chamber and PR-free DMEM with $10 \%$ FBS was added into the bottom chamber as a chemo-attractant. Subsequent to a $24 \mathrm{~h}$ incubation at $37^{\circ} \mathrm{C}$ in a humidified atmosphere with $5 \% \mathrm{CO}_{2}$, the upper surfaces of the membranes were swabbed to remove non-invasive cells and the cells attached onto the lower surface were fixed in $100 \%$ methanol, stained with hematoxylin and eosin (Beyotime Institute of Biotechnology, Haimen, China), and counted under an inverted light microscope equipped (Eclipse 50i) with a color camera (DS-Fi2) (both Nikon Corporation, Tokyo, Japan) at magnification, $\mathrm{x} 200$. A total of 5 randomly selected fields were analyzed from each group. Values represent the percentage of invasive cells relative to the controls (as 100\%).

Western blot analysis. Cells were collected and lysed in lysis buffer (Beyotime Institute of Biotechnology). The lysates were separated using centrifugation at $4^{\circ} \mathrm{C}$ for $15 \mathrm{~min}$ at $13,000 \mathrm{x} \mathrm{g}$. 
Protein concentration was determined using a bicinchoninic acid assay kit (Pierce; Thermo Fisher Scientific, Inc.) with a Varioskan multimode microplate spectrophotometer (Thermo Fisher Scientific, Inc.). Total protein (30 $\mu \mathrm{g} /$ lane) was separated using 12\% SDS-PAGE and transferred to a PVDF membrane (EMD Millipore). The membrane was blocked using $5 \%$ non-fat milk at $37^{\circ} \mathrm{C}$ for $1 \mathrm{~h}$, and subsequently incubated with aforementioned appropriate antibodies at $37^{\circ} \mathrm{C}$ for $1 \mathrm{~h}$. Blots were visualized using an enhanced chemiluminescence kit (EMD Millipore). Digital images of blots were captured using a ChemiDoc $\mathrm{XRS}^{+}$system and analyzed using Image $\mathrm{Lab}^{\mathrm{TM}}$ software (version 5.2) (both Bio-Rad Laboratories, Inc., Hercules, CA, USA).

Gelatin zymography assay. The activity of MMP-2 and MMP-9 were analyzed using a gelatin zymography assay as previous described (25). Cells $\left(2 \times 10^{5}\right.$ cells $\left./ \mathrm{ml}\right)$ were seeded (2 ml) into a six-well plate. When $80 \%$ confluence was achieved, the cells were treated as indicated. Following treatment, the conditioned medium was collected and centrifuged at $112 \times \mathrm{g}$ for $5 \mathrm{~min}$ at $4^{\circ} \mathrm{C}$ to remove the dead cell debris. The conditioned medium with sample buffer $(0.5 \mathrm{M}$ Tris- $\mathrm{HCl}$ pH 6.8, buffer with $30 \%$ glycerin, $0.05 \%$ Bromophenol blue and $6 \% \mathrm{SDS}, \mathrm{v} / \mathrm{v}$ at 2:1) was subjected to $10 \%$ SDS-PAGE containing $0.1 \%$ gelatin. Following electrophoresis, the gels were washed twice with rinsing buffer $(50 \mathrm{mM}$ Tris- $\mathrm{HCl}$ $\mathrm{pH}$ 7.6, with $5 \mathrm{mM}, \mathrm{CaCl}_{2}, 1 \mu \mathrm{M} \mathrm{ZnCl}_{2}$ and $2.5 \%$ Triton $\mathrm{X}-100)$ to remove the SDS and incubated for $36 \mathrm{~h}$ at $37^{\circ} \mathrm{C}$ in incubating buffer $\left(50 \mathrm{mM}\right.$ Tris- $\mathrm{HCl}$ buffer with $5 \mathrm{mM} \mathrm{CaCl}_{2}$, $1 \mu \mathrm{M} \mathrm{ZnCl}_{2}$ ). The gels were subsequently stained with $0.1 \%$ Coomassie Brilliant Blue R250 (Beijing Solarbio Science \& Technology Co., Ltd., Beijing, China) for $1 \mathrm{~h}$ at room temperature, followed with destaining using $10 \%$ acetic acid and $10 \%$ methanol. The images of the gels were captured using the ChemiDoc $\mathrm{XRS}^{+}$system and analyzed with Image $\mathrm{Lab}^{\mathrm{TM}}$ software (version 5.2).

Reverse transcription-quantitative polymerase chain reaction $(R T-q P C R)$. Total RNA was extracted following treatment using an RNA Extraction kit (cat. no. 9767; Takara Biotechnology Co., Ltd., Dalian, China) according to the manufacturer's protocol. cDNA was synthesized using a strand complementary DNA synthesis kit (cat. no. 6210A; Takara Biotechnology Co., Ltd.) according to the manufacturer's protocol. mRNA expression was measured using SYBR Green PCR Core reagents (cat. no. RR820A, TaKaRa). The reaction were conducted in 96-well plate and the reaction volume for per well was $20 \mu \mathrm{l}$, including $2 \mu \mathrm{l}(100 \mathrm{ng}) \mathrm{cDNA}, 10 \mu \mathrm{l} \mathrm{SYBR}$ Premix Ex Taq II, $0.8 \mu \mathrm{l}(10 \mu \mathrm{M})$ of both forward and reverse

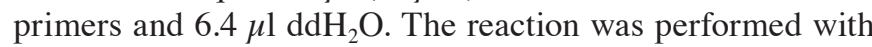
a CFX Connect ${ }^{\mathrm{TM}}$ Real-Time PCR Detection system (Bio-Rad Laboratories, Inc.). The following primers were synthesized by Sangon Biotech Co., Ltd. (Shanghai, China) and used in the present study: MMP-9 forward, 5'-GTGGGGATTTAC ATGGCACT-3' and reverse, 5'-AAAGCCTATTTCTGC CAGGAC-3' (26); $\beta$-actin forward, 5'-AGTTGCGTTACA CCCTTTC-3' and reverse, 5'-CCTTCACCGTTCCAG TTT-3' (27). The thermocycling conditions maintained were as follows: $30 \mathrm{sec}$ at $95^{\circ} \mathrm{C}$; followed by 40 cycles at $95^{\circ} \mathrm{C}$ for $5 \mathrm{sec}$; and $60^{\circ} \mathrm{C}$ for $30 \mathrm{sec}$. The melting curve was analyzed at $65-95^{\circ} \mathrm{C}$ to detect a single gene-specific peak and verify the absence of primer dimer peaks. The MMP-9 mRNA level was quantified relative to $\beta$-actin mRNA expression using the $2^{-\Delta \Delta \mathrm{Cq}}$ method (28).

Statistical analysis. Data are expressed as the mean \pm standard error of the mean following $\geq 3$ independent experiments. Statistically significant differences were calculated using one-way analysis of variance followed by the Bonferroni's post hoc test for multiple-group comparisons by using SPSS Statistics v.17.0 (SPSS, Inc., Chicago, IL, USA). P<0.05 was considered to indicate a statistically significant difference.

\section{Results}

Unlike OHT, baicalein is able to prevent E2-induced invasion and MMP-9 expression and activity in MCF-7 human breast cancer cells. To assess the effects of anti-estrogenic agents tamoxifen and baicalein on E2-induced invasion, estrogen-sensitive MCF-7 breast cancer cells were treated with OHT or baicalein in the presence of E2 for $24 \mathrm{~h}$. It was observed that OHT failed to suppress E2-induced invasion, while baicalein was able to significantly suppress this effect compared with the E2-treated control group (Fig. 1A). MMPs perform essential roles in processes associated with tumor invasion and metastasis, when cells become invasive they often produce proteolytic enzymes, which can degrade the majority of the extracellular matrix (29). Next, the enzyme activity of MMP-2 and MMP-9 was addressed following the above treatment. It was demonstrated that E2 or E2 plus OHT promoted MMP-9 activity, while baicalein exerted a significant suppression of E2-enhanced MMP-9 activity compared with the E2-treated group (Fig. 1B). However, no significant differences were identified among the activity of MMP-2 across all treatment groups (Fig. 1B). Additionally, western blot analysis and RT-qPCR analyses were performed to further confirm the changes observed in MMP-9 activity. The protein and mRNA expression levels were upregulated following E2 or E2 plus OHT treatment compared with the untreated control group. However, the two expression levels were significantly downregulated in the presence of baicalein compared with the E2-treated group (Fig. 1C and D).

GPR30 mediates cell invasion and MMP-9 activity and expression induced by E2. Since tamoxifen acts as an ER $\alpha$ antagonist but agonist for the GPR30, it was hypothesized that the mechanism by which estrogen induced invasiveness occurs through GPR30 activation. To validate the potential role of GPR30 in cell invasion, and MMP-9 activity and expression, MCF-7 cells were pretreated with the GPR30 antagonist G15 prior to stimulation with E2. The results demonstrated that G15 effectively suppressed E2-induced cell invasion compared with the E2-treated group (Fig. 2A). G15 significantly reduced MMP-9 activity compared with the E2-treated group (Fig. 2B). Furthermore, MMP-9 protein expression in G15 pretreated groups was significantly lower compared with that in the E2-induced group (Fig. 2C). Similar changes in MMP-9 mRNA expression were observed (Fig. 2D). This suggests that the effects of E2 on cell invasion and MMP-9 are mediated through the activation of GPR30. 

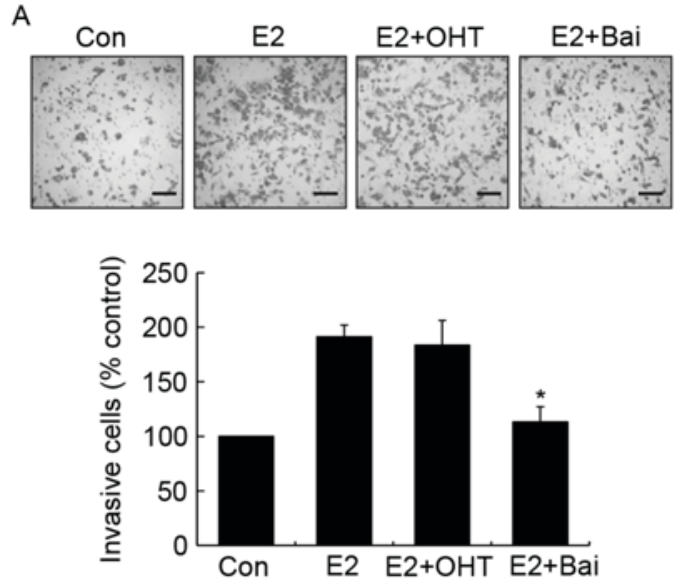

C
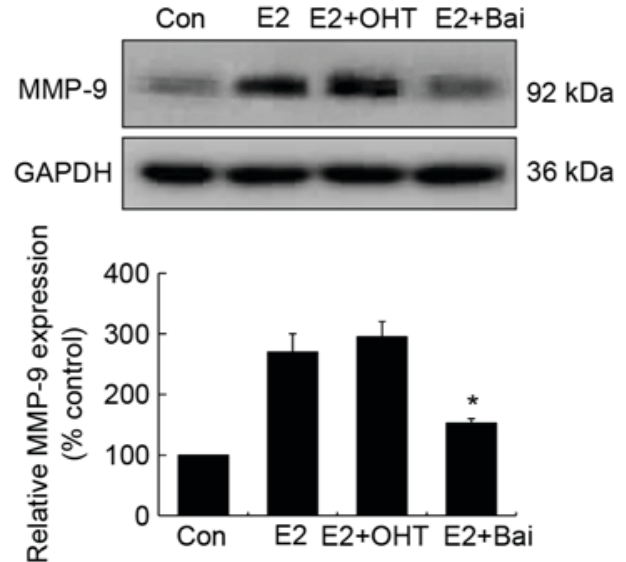
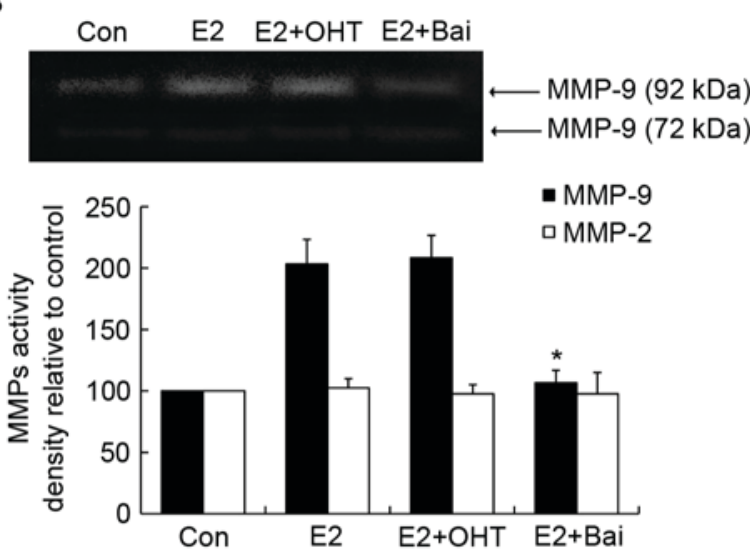

$\mathrm{D}$

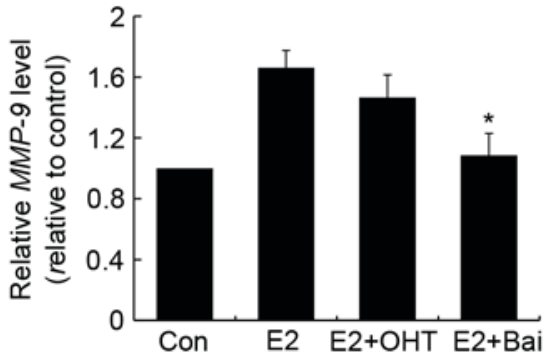

Figure 1. Effects of OHT and baicalein on E2-induced cell invasion, and the activity and expression of MMP-9 in MCF-7 cells. Cells were treated with DMSO $(0.01 \%)$, E2 $(1 \mathrm{nM})$, E2 $(1 \mathrm{nM})$ plus OHT $(1 \mu \mathrm{M})$ or E2 $(1 \mathrm{nM})$ plus baicalein (Bai, $10 \mu \mathrm{M})$ for $24 \mathrm{~h}$. OHT and baicalein was added $30 \mathrm{~min}$ prior to E2 stimulation. (A) Invasive cells were stained using hematoxylin and eosin (magnification, $\mathrm{x} 200$, scale bar=500 $\mu \mathrm{m}$ ). (B) The activity of MMP-2/9 was measured using a gelatin zymography assay. A representative zymographic gel is illustrated, where the clear bands represent collagenases MMP-2 and MMP-9. Results of densitometrical analysis are illustrated. (C) The expression of MMP-9 was determined using western blotting. Densitometric analysis represents the ratios of MMP-9 relative to GAPDH. (D) MMP-9 mRNA expression was detected using reverse transcription-quantitative polymerase chain reaction analysis and fold-changes were normalized to $\beta$-actin mRNA level. Data are presented as the mean \pm standard error of the mean, and normalized as a percentage of the control. "P<0.05 vs. the E2-treated group. OHT, 4-hydroxytamoxifen; E2, 17 $\beta$-estradiol; MMP, matrix metalloproteinase; cont, control; Bai, baicalein.

Similar to the effects of $G 15$, baicalein inhibits $G-1$ induced cell invasion and MMP-9 activity and expression in MCF-7 cells. To confirm whether baicalein exerted its effects by interfering with GPR30 activation, the action of baicalein on GPR30 agonist G-1 induced invasion and MMP-9 activity and expression was investigated, whereby G15 was used as a positive control. As expected, treatment with G-1 resulted in an increase in cell invasion, which was significantly suppressed by G15 or baicalein pretreatment (Fig. 3A). In addition, it was revealed that treatment with baicalein led to significant suppression of G-1-induced MMP-9 activation (Fig. 3B), similar to the effects of G15. In addition, the upregulation of MMP-9 protein and mRNA expression induced by G-1 was significantly inhibited following baicalein treatment (Fig. 3C and D).

\section{Discussion}

While anti-estrogenic agents have been used successfully, breast cancer remains the leading cause of cancer-associated mortality among females worldwide (30). Additionally, aromatase inhibitors, which depress E2 synthesis, are more efficacious and produce significantly lower recurrence rates when compared with tamoxifen (31), indicating that solely targeting ER $\alpha$ to inhibit the action of estrogen may be suboptimal. GPR30 is independent of $\mathrm{ER} \alpha$ status in breast cancer cells and tissue samples, and its action differs from the classical nuclear ERs, $\operatorname{ER} \alpha$ and $\operatorname{ER} \beta$ (32). Upregulation and activation of GPR30 promotes the progression of breast cancer, and GPR30 is considered a biological target for innovative therapeutic strategies (33). Research has demonstrated that overexpression of GPR30 in primary tumors is positively correlated with the metastatic phenotype of breast cancer $(6,7)$, and GPR30 knockout MMTV-PyMT mice possess less aggressive tumors and fewer metastases (8). In the present study, an ER $\alpha$ - and GPR30-positive MCF-7 breast cancer cell line was used as a model system. It was demonstrated that the inhibition of GPR30 activation by its specific antagonist G15 significantly suppressed E2- or G-1-induced invasion, which 
A
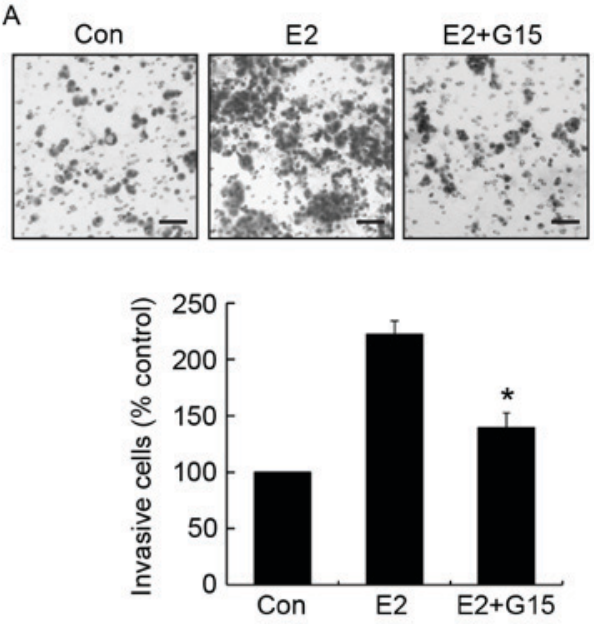

C
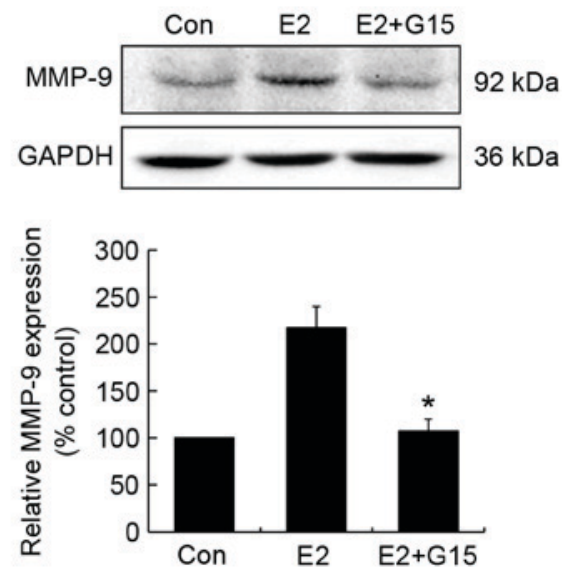

B
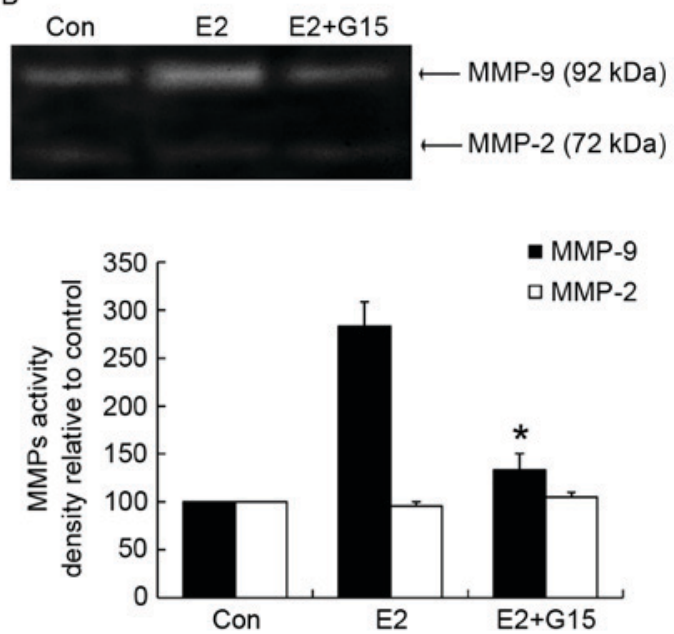

D

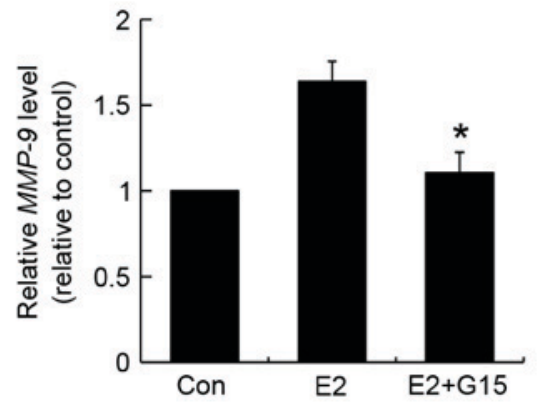

Figure 2. Inhibition of GPR30 by antagonist G15 impedes E2-induced cell invasion, and MMP-9 activation and expression. MCF-7 cells were pretreated with or without $\mathrm{G} 15(1 \mu \mathrm{M})$ for 30 min prior to treatment with E2 $(1 \mathrm{nM})$ for $24 \mathrm{~h}$. (A) Invasive ability of the cells was measured using a Transwell chamber assay (magnification, $\mathrm{x} 200$, scale bar=500 $\mu \mathrm{m}$ ). (B) The activity of MMP-9 was measured using a gelatin zymography assay. (C) The expression of MMP-9 was determined using western blotting. (D) MMP-9 mRNA expression was detected using reverse transcription-quantitative polymerase chain reaction analysis. Data are presented as the mean \pm standard error of the mean, and normalized as a percentage of the control. *P<0.05 vs. the E2-treated group. GPR30, G protein-coupled receptor 30; E2, 17 $\beta$-estradiol; MMP, matrix metalloproteinase; cont, control.

is the initial stage of metastasis. Furthermore, GPR30 inhibition significantly reduced the E2- or G-1-induced increase in MMP-9 expression and proteolytic activity, suggesting that GPR30 regulates metastasis by enhancing cell invasive ability.

Tamoxifen was initially designed as an anti-estrogenic agent, but has also been demonstrated to partially induce estrogenic activity (34). It has been revealed to enhance the migration and invasion abilities of ER $\alpha$-negative SK-BR-3 breast cancer cells (35), and promotes the proliferation and invasion of endometrial cancer cells, similar to the effects of E2 (36). Furthermore, previous studies have revealed that tamoxifen can increase invasiveness and the expression of MMPs in MCF-7 cells in vitro $(37,38)$. In the current study, it was demonstrated that although OHT could inhibit the function of ER $\alpha$, it failed to prevent E2-induced cell invasion, and MMP-9 activation and upregulation. However, the E2-stimulated activation and upregulation of MMP-9 were significantly inhibited by treatment of cells with the GPR30 antagonist G15.
In addition, tamoxifen could perform as a GPR30 agonist. The results of the present study indicate that E2 promoted MMP-9 upregulation and expression through GPR30, instead of ER $\alpha$. Furthermore, these results suggest that GPR30 performs an important role in maintaining the responsiveness of breast cancer cells to E2 in the pharmacological blockade of ER $\alpha$. Therefore, antagonistic action on ER $\alpha$ and GPR30 may be a rational strategy for the treatment of ER $\alpha$-positive breast cancer.

Emerging evidence suggests that administering endocrine agents, including tamoxifen has effects beyond their initially described mechanism of action. For example, tamoxifen has been demonstrated to promote the induction of epidermal growth factor receptor, human epidermal growth factor receptor-2 and insulin-like growth factor I (IGF-I) receptor, which subsequently activates various cellular kinase cascades, and elicits tamoxifen resistance (39). In addition, previous studies demonstrated that GPR30 is involved in the development 

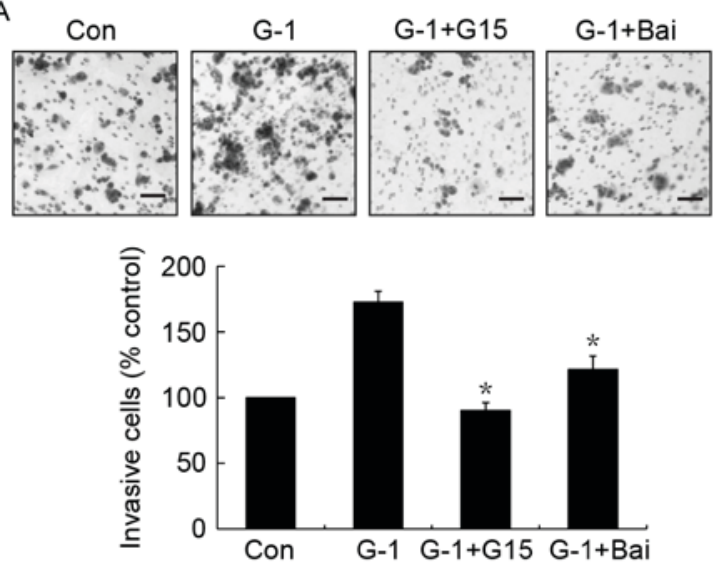

C
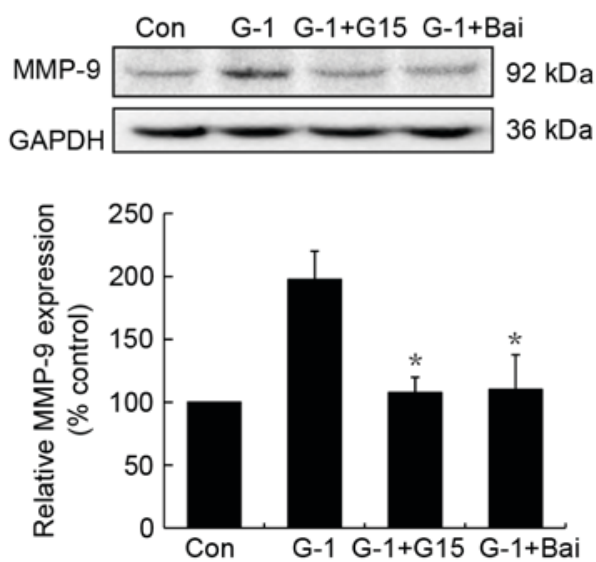
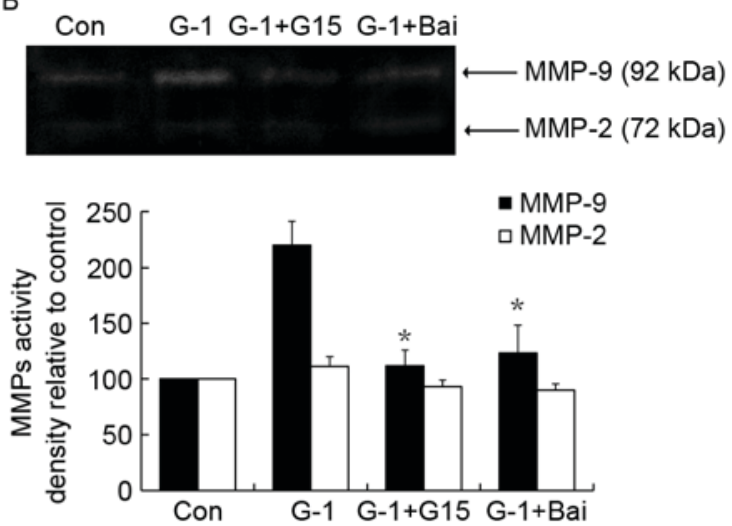

D

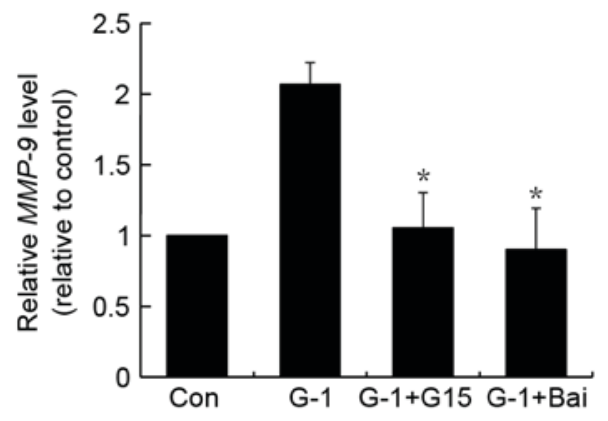

Figure 3. Baicalein suppresses GPR30 agonist G-1-induced cell invasion, and MMP-9 activation and expression. MCF-7 cells were pretreated with G15 (1 $\mu \mathrm{M})$ or baicalein $(10 \mu \mathrm{M})$ for $30 \mathrm{~min}$ and followed by treatment with G-1 $(1 \mu \mathrm{M})$ for $24 \mathrm{~h}$. (A) Invasive ability of the cells was measured using a Transwell chamber assay (magnification, $x 200$, scale bar=500 $\mu \mathrm{m}$ ). (B) The activity of MMP-9 was measured using a gelatin zymography assay. (C) The expression of MMP-9 was determined using western blotting. (D) The mRNA expression of MMP-9 was detected using reverse transcription-quantitative polymerase chain reaction analysis. Data are presented as the mean \pm standard error of the mean, and normalized as a percentage of the control. "P<0.05 vs. the G-1 treated group. GPR30, G protein-coupled receptor 30; MMP, matrix metalloproteinase; cont, control; bai, baicalein.

of tamoxifen resistance and appearance of metastasis $(40,41)$. GPR30 expression is significantly increased in tamoxifen resistant tumor tissue compared with primary tumors from the same patients (40). Furthermore, Mo et al (41) revealed that the expression of GPR30 was significantly increased in metastatic tumor compared with their corresponding primary tumor samples from 53 GPR30-positive patients with tamoxifen recurrence and that the GPR30 antagonist was able to reverse tamoxifen-induced resistance. Thus, it is suggested that inhibiting GPR30 signaling activation may provide an alternative therapeutic strategy for treating tamoxifen-resistant patients with breast cancer.

A previous study demonstrated that baicalein exhibits effective inhibitory activities against E2/IGF-1-induced cellular proliferation and colony formation in human breast carcinoma cells (42). In addition, the binding ability of baicalein to the ER was confirmed through a competitive ligand-binding assay $(43,44)$. Notably, baicalein antagonized the estradiol-induced estrogen responsive elements response in a dose dependent manner (21). Unlike genistein, an isomer of baicalein, it does not exhibit a biphasic effect on ER $\alpha$, thus there is no exhibition of estrogenic activity to transactivate ER $\alpha$ at low concentrations (21). These investigations propose that baicalein exerts anti-estrogenic activity and inhibitory effects on ER $\alpha$ transcriptional function. Recently, the authors of the current study demonstrated that baicalein suppresses E2-promoted migration and invasion in MCF-7 (GPR30/ER $\alpha$-positive) and SK-BR-3 (GPR30-positive/ER $\alpha$-negative) breast cancer cells (23). Furthermore, it was revealed that baicalein significantly inhibited E2- or G1-induced GPR30 signal activation and GPR30 target genes, cysteine-rich 61, and connective tissue growth factor upregulation (23).

In the present study, it was demonstrated that baicalein significantly suppressed E2- or G-1 induced cell invasion, and MMP-9 upregulation and activation, exhibiting a similar effect to G15, but a reverse effect compared with OHT. This indicates that baicalein exerts a different activity to tamoxifen, and may possess dual inhibitory effects on ER $\alpha$ and GPR30 signaling. However, this hypothesis requires further investigation. To further investigate the underlying mechanism of baicalein, a detailed explanation of the signaling pathway by which GPR30 regulates MMP-9 expression and activation 
is required, as well as the molecular mechanisms by which baicalein influences GPR30 signaling. In addition, in vivo studies are warranted to confirm the effects observed in the current study.

In conclusion, baicalein, but not OHT, significantly attenuated E2-induced invasion, and MMP-9 upregulation and activation in MCF-7 breast cancer cells, which may be due to their different actions on GPR30. As cell invasion and MMP-9 activation positively correlates with cancer metastasis, it could be suggested that the inhibition of GPR30 activation may be a promising approach to reduce metastasis, and improve the efficacy of anti-estrogens. Targeting ER $\alpha$ and GPR30 receptors may achieve additional therapeutic benefits for the treatment of patients with breast cancer.

\section{Acknowledgements}

The present study was supported by The National Natural Science Foundation of China (grant nos. 81302804 and 81560598), The Natural Science Foundation of Guizhou Province of China [grant no. QKHJ (2014) 2007], Postdoctoral Science Foundation of China (grant no. 2015M582749XB), Science Foundation of Guiyang Science and Technology Bureau [grant no. (20141001)06], Science and technology innovation advanced individual of Guizhou educational department [grant no. QJHKY (2015)492], Startup Foundation for Doctors of Guiyang Medical University [grant no. (2013)09], The Foundation for Training Programs of Innovation and Entrepreneurship for Undergraduates of Guiyang Medical University (grant no. 201410660038), The Innovated Team of the Education Department of Guizhou Province (grant no. 2014-31), The Innovation team of Guizhou Province [grant no. (2015)4025], The Program for New Century Excellent Talents in University (grant no. NCET-13-0747), The High level Innovation Talents (grant no. 2015-4029).

\section{References}

1. Cordera F and Jordan VC: Steroid receptors and their role in the biology and control of breast cancer growth. Semin Oncol 33: 631-641, 2006.

2. Huang B, Warner M and Gustafsson JÅ: Estrogen receptors in breast carcinogenesis and endocrine therapy. Mol Cell Endocrinol 418: 240-244, 2015.

3. Johnston SR: New strategies in estrogen receptor-positive breast cancer. Clin Cancer Res 16: 1979-1987, 2010.

4. Jager NG, Linn SC, Schellens JH and Beijnen JH: Tailored tamoxifen treatment for breast cancer patients: A perspective. Clin Breast Cancer 15: 241-244, 2015.

5. Prossnitz ER and Arterburn JB: International union of basic and clinical pharmacology. XCVII. G protein-coupled estrogen receptor and its pharmacologic modulators. Pharmacol Rev 67: 505-540, 2015

6. Filardo EJ, Graeber CT, Quinn JA, Resnick MB, Giri D, DeLe1lis RA, Steinhoff MM and Sabo E: Distribution of GPR30, a seven membrane-spanning estrogen receptor, in primary breast cancer and its association with clinicopathologic determinants of tumor progression. Clin Cancer Res 12: 6359-6366, 2006.

7. Liu Q, Li JG, Zheng XY, Jin F and Dong HT: Expression of CD133, PAX2, ESA, and GPR30 in invasive ductal breast carcinomas. Chin Med J (Engl) 122: 2763-2769, 2009.

8. Marjon NA, Hu C, Hathaway HJ and Prossnitz ER: G protein-coupled estrogen receptor regulates mammary tumorigenesis and metastasis. Mol Cancer Res 12: 1644-1654, 2014.

9. Revankar CM, Cimino DF, Sklar LA, Arterburn JB and Prossnitz ER: A transmembrane intracellular estrogen receptor mediates rapid cell signaling. Science 307: 1625-1630, 2005.
10. Yilmaz M, Christofori G and Lehembre F: Distinct mechanisms of tumor invasion and metastasis. Trends Mol Med 13: 535-541, 2007.

11. Kessenbrock K, Plaks V and Werb Z: Matrix metalloproteinases: Regulators of the tumor microenvironment. Cell 141: 52-67, 2010.

12. Li HC, Cao DC, Liu Y, Hou YF, Wu J, Lu JS, Di GH, Liu G, Li FM, Ou ZL, et al: Prognostic value of matrix metalloproteinases (MMP-2 and MMP-9) in patients with lymph node-negative breast carcinoma. Breast Cancer Res Treat 88: 75-85, 2004.

13. Liu HD, Yan Y, Cao XF, Tan PZ, Wen HX, Lv CM, Li XM and Liu GY: The expression of a novel estrogen receptor, GPR30, in epithelial ovarian carcinoma and its correlation with MMP-9. Sheng Li Xue Bao 62: 524-528, 2010 (In Chinese).

14. Long L, Cao Y and Tang LD: Transmembrane estrogen receptor GPR 30 is more frequently expressed in malignant than benign ovarian endometriotic cysts and correlates with MMP-9 expression. Int J Gynecol Cancer 22: 539-545, 2012.

15. Yan Y, Liu H, Wen H, Jiang X, Cao X, Zhang G and Liu G: The novel estrogen receptor GPER regulates the migration and invasion of ovarian cancer cells. Mol Cell Biochem 378: 1-7, 2013.

16. Rossi RE, Pericleous M, Mandair D, Whyand T and Caplin ME: The role of dietary factors in prevention and progression of breast cancer. Anticancer Res 34: 6861-6875, 2014.

17. Hui C, Qi X, Qianyong Z, Xiaoli P, Jundong Z and Mantian M: Flavonoids, flavonoid subclasses and breast cancer risk: A meta-analysis of epidemiologic studies. PLoS One 8: e54318, 2013.

18. Cho YA, Kim J, Park KS, Lim SY, Shin A, Sung MK and Ro J: Effect of dietary soy intake on breast cancer risk according to menopause and hormone receptor status. Eur J Clin Nutr 64: 924-932, 2010.

19. Takemura H, Sakakibara H, Yamazaki S and Shimoi K: Breast cancer and flavonoids - a role in prevention. Curr Pharm Des 19: 6125-6132, 2013.

20. Moon YJ, Wang X and Morris ME: Dietary flavonoids: Effects on xenobiotic and carcinogen metabolism. Toxicol In Vitro 20: 187-210, 2006.

21. Po LS, Chen ZY, Tsang DS and Leung LK: Baicalein and genistein display differential actions on estrogen receptor (ER) transactivation and apoptosis in MCF-7 cells. Cancer Lett 187: 33-40, 2002.

22. Chang HT, Chou CT, Kuo DH, Shieh P, Jan CR and Liang WZ: The mechanism of $\mathrm{Ca}(2+)$ movement in the involvement of baicalein-induced cytotoxicity in ZR-75-1 human breast cancer cells. J Nat Prod 78: 1624-1634, 2015.

23. Shang D, Li Z, Zhu Z, Chen H, Zhao L, Wang X and Chen Y: Baicalein suppresses 17- $\beta$-estradiol-induced migration, adhesion and invasion of breast cancer cells via the $\mathrm{G}$ protein-coupled receptor 30 signaling pathway. Oncol Rep 33: 2077-2085, 2015.

24. Wang L, Ling Y, Chen Y, Li CL, Feng F, You QD, Lu N and Guo QL: Flavonoid baicalein suppresses adhesion, migration and invasion of MDA-MB-231 human breast cancer cells. Cancer Lett 297: 42-48, 2010.

25. Chen P, Lu N, Ling Y, Chen Y, Hui H, Lu Z, Song X, Li Z, You Q and Guo Q: Inhibitory effects of wogonin on the invasion of human breast carcinoma cells by downregulating the expression and activity of matrix metalloproteinase-9. Toxicology 282: 122-128, 2011.

26. Pello OM, De Pizzol M, Mirolo M, Soucek L, Zammataro L, Amabile A, Doni A, Nebuloni M, Swigart LB, Evan GI, et al: Role of c-MYC in alternative activation of human macrophages and tumor-associated macrophage biology. Blood 119: 411-421, 2012.

27. Ferreira E and Cronjé MJ: Selection of suitable reference genes for quantitative real-time PCR in apoptosis-induced MCF-7 breast cancer cells. Mol Biotechnol 50: 121-128, 2012.

28. Livak KJ and Schmittgen TD: Analysis of relative gene expression data using real-time quantitative PCR and the 2(-Delta Delta C(T)) method. Methods 25: 402-408, 2001.

29. Gialeli C, Theocharis AD and Karamanos NK: Roles of matrix metalloproteinases in cancer progression and their pharmacological targeting. FEBS J 278: 16-27, 2011.

30. Jemal A, Bray F, Center MM, Ferlay J, Ward E and Forman D: Global cancer statistics. CA Cancer J Clin 61: 69-90, 2011.

31. Dowsett M, Cuzick J, Ingle J, Coates A, Forbes J, Bliss J, Buyse M, Baum M, Buzdar A, Colleoni M, et al: Meta-analysis of breast cancer outcomes in adjuvant trials of aromatase inhibitors versus tamoxifen. J Clin Oncol 28: 509-518, 2010.

32. Maggiolini M and Picard D: The unfolding stories of GPR30, a new membrane-bound estrogen receptor. J Endocrinol 204: $105-114,2010$. 
33. Wang D, Hu L, Zhang G, Zhang L and Chen C: G protein-coupled receptor 30 in tumor development. Endocrine 38: 29-37, 2010.

34. Catalano S, Giordano C, Panza S, Chemi F, Bonofiglio D, Lanzino M, Rizza P, Romeo F, Fuqua SA, Maggiolini M, et al: Tamoxifen through GPER upregulates aromatase expression: A novel mechanism sustaining tamoxifen-resistant breast cancer cell growth. Breast Cancer Res Treat 146: 273-285, 2014.

35. Ruan SQ, Wang ZH, Wang SW, Fu ZX, Xu KL, Li DB and Zhang SZ: Heregulin- $\beta 1$-induced GPR30 upregulation promotes the migration and invasion potential of $\mathrm{SkBr} 3$ breast cancer cells via ErbB2/ErbB3-MAPK/ERK pathway. Biochem Biophys Res Commun 420: 385-390, 2012.

36. Du GQ, Zhou L, Chen XY, Wan XP and He YY: The G protein-coupled receptor GPR30 mediates the proliferative and invasive effects induced by hydroxytamoxifen in endometrial cancer cells. Biochem Biophys Res Commun 420: 343-349, 2012.

37. Thompson EW, Reich R, Shima TB, Albini A, Graf J, Martin GR, Dickson RB and Lippman ME: Differential regulation of growth and invasiveness of MCF-7 breast cancer cells by antiestrogens. Cancer Res 48: 6764-6768, 1988.

38. Nilsson UW, Garvin S and Dabrosin C: MMP-2 and MMP-9 activity is regulated by estradiol and tamoxifen in cultured human breast cancer cells. Breast Cancer Res Treat 102: 253-261, 2007.
39. Fedele P, Calvani N, Marino A, Orlando L, Schiavone P, Quaranta A and Cinieri S: Targeted agents to reverse resistance to endocrine therapy in metastatic breast cancer: Where are we now and where are we going? Crit Rev Oncol Hematol 84: 243-251, 2012.

40. Ignatov A, Ignatov T, Weissenborn C, Eggemann $\mathrm{H}$, Bischoff J, Semczuk A, Roessner A, Costa SD and Kalinski T: G-protein-coupled estrogen receptor GPR30 and tamoxifen resistance in breast cancer. Breast Cancer Res Treat 128: 457-466, 2011.

41. Mo Z, Liu M, Yang F, Luo H, Li Z, Tu G and Yang G: GPR30 as an initiator of tamoxifen resistance in hormone-dependent breast cancer. Breast Cancer Res 15: R114, 2013.

42. Lin CW, Yang LY, Shen SC and Chen YC: IGF-I plus E2 induces proliferation via activation of ROS-dependent ERKs and JNKs in human breast carcinoma cells. J Cell Physiol 212: 666-674, 2007.

43. Branham WS, Dial SL, Moland CL, Hass BS, Blair RM, Fang H, Shi L, Tong W, Perkins RG and Sheehan DM: Phytoestrogens and mycoestrogens bind to the rat uterine estrogen receptor. J Nutr 132: 658-664, 2002.

44. Shenouda NS, Zhou C, Browning JD, Ansell PJ, Sakla MS, Lubahn DB and Macdonald RS: Phytoestrogens in common herbs regulate prostate cancer cell growth in vitro. Nutr Cancer 49: 200-208, 2004 